\title{
Endotoxin-induced disseminated intravascular coagulation in rabbits: Effect of recombinant hirudin on hemostatic parameters, fibrin deposits, and mortality
}

\author{
JOSÉ HERMIDA, RAMÓN MONTES, JOSÉ ANTONIO PÁRAMO, and EDUARDO ROCHA \\ PAMPLONA, SPAIN
}

\begin{abstract}
We evaluated the effect of $r$-hirudin on an experimental model of disseminated infravascular coagulation (DIC) in rabbits, through the continuous infusion of 100 $\mu \mathrm{g} / \mathrm{kg} / \mathrm{hr}$ of Escherichia coli endotoxin for a period of 6 hours. r-Hirudin $(0.05,0.3$, and $0.6 \mathrm{mg} / \mathrm{kg} / \mathrm{hr}$ ) as treatment, or saline solution as placebo, were administered simultaneously with endotoxin. Severe DIC in the endotoxin control group was shown by impairment in hemostatic parameters, kidney fibrin deposition, and a high mortality rate. Medium and high doses of r-hirudin led to an improvement in such DIC-related parameters as platelet numbers and fibrinogen and protein $\mathrm{C}$ concentrations. High-dose r-hirudin also reduced consumption of antithrombin III (ATIII). All doses of $r$-hirudin prevented decreases in tissue plasminogen activator (A-PA) and reduced the increase in plasminogen activator inhibitor-1 (PAl-1) activity observed at 2 hours after endotoxin administration. A significant reduction in kidney fibrin deposition was seen in medium- and high-dose r-hirudin groups. Additionally, the mortality rate in rabbits receiving medium- and high-dose r-hirudin was $10 \%$, and that in rabbits receiving low-dose r-hirudin was $20 \%$, as compared with a mortality rate of $70 \%$ in the control group. Protein $\mathrm{C}$ activity was significantly lower $(p<0.001)$ in nonsurviving rabbits. Moreover, there was a strong positive correlation $(r=0.68, p<0.001)$ between protein $C$ consumption and kidney fibrin deposition. We conclude that $r$-hirudin can be a useful drug in the clinical treatment of DIC. ( $J$ Lab Clin Med 1998;131:77-83)
\end{abstract}

\begin{abstract}
Abbreviations: $\mathrm{ANOVA}=$ analysis of variance; $\mathrm{ATIII}=$ antithrombin III; DIC = disseminated intravascular coagulation; $\mathrm{K}_{3}$-EDTA = tripotassium salt of ethylenediaminetetraacetic acid; LPS = lipopolysaccharide; $\mathrm{MOF}=$ multiple organ failure; $\mathrm{PAl}-1=$ plasminogen activator inhibitor-1; t-PA = tissue plasminogen activator
\end{abstract}

From the Laboratory of Vascular Biology and Thrombosis, Hematology Service, School of Medicine, University of Navarra.

Supported by Grant PM 92-0167 from the Dirección General de Investigación Científica y Técnica of the Ministerio de Educación y Ciencia, Spain.

Submitted for publication April 16, 1997; revision submitted July 2, 1997; accepted Aug. 4, 1997.

Reprint requests: E. Rocha, Hematology Service, University Clinic of Navarra, Avenida Pio XII, s/n, PO 4209, Paraplona, Spain.

Copyright (1) 1998 by Mosby, Inc.

$0022-2143 / 98 \$ 5.00+0 \quad \mathbf{5 / 1 / 8 5 6 7 6}$
D

IC is a serious and frequent complication of gram-negative bacterial sepsis. ${ }^{1}$ Despite the use of potent antibiotics and intensive supportive care, mortality among patients with sepsisinduced DIC remains close to $60 \%{ }^{2}$

Gram-negative bacteria include in their outer membrane a molecule called endotoxin or LPS. This substance leads monocytes and endothelial cells to generate several cytokines that in turn activate coagulation, mainly through the extrinsic pathway. ${ }^{3}$ As a result, large amounts of thrombin are generated. Thrombin transforms fibrinogen into fibrin and 
Table I. Hemostatic parameters 2 and 6 hours after endotoxin infusion into rabbits in five different groups. Data shown as mean \pm SEM percent of the basal value

\begin{tabular}{llcccc}
\hline \multicolumn{1}{c}{ Group } & \multicolumn{1}{c}{$\begin{array}{c}\text { Platelets } \\
(\%)\end{array}$} & $\begin{array}{c}\text { Fibrinogen } \\
(\%)\end{array}$ & $\begin{array}{c}\text { AT III } \\
\text { (\%) }\end{array}$ & $\begin{array}{c}\text { Protein C } \\
\text { (\%) }\end{array}$ \\
\hline Saline control & $2 \mathrm{hr}$ & $96.29 \pm 12.6 \dagger$ & $94.68 \pm 10.2$ & $93.04 \pm 5.39$ & $96.15 \pm 2.88 \neq$ \\
& $6 \mathrm{hr}$ & $96.29 \pm 6.54 \ddagger$ & $94.35 \pm 9.39 \neq$ & $89.39 \pm 4.76^{*}$ & $96.73 \pm 3.50 \neq$ \\
Endotoxin control & $2 \mathrm{hr}$ & $48.76 \pm 4.58$ & $95.53 \pm 3.86$ & $87.72 \pm 3.93$ & $58.65 \pm 5.20$ \\
& $6 \mathrm{hr}$ & $20.31 \pm 3.53$ & $58.22 \pm 5.06$ & $73.07 \pm 5.80$ & $15.15 \pm 3.30$ \\
Hirudin $(0.05 \mathrm{mg} / \mathrm{kg} / \mathrm{hr})$ & $2 \mathrm{hr}$ & $61.65 \pm 5.65$ & $89.75 \pm 3.89$ & $88.35 \pm 2.15$ & $67.80 \pm 5.08$ \\
Hirudin $(0.3 \mathrm{mg} / \mathrm{kg} / \mathrm{hr})$ & $6 \mathrm{hr}$ & $31.18 \pm 5.67$ & $73.30 \pm 5.72$ & $80.13 \pm 4.89$ & $17.84 \pm 4.43$ \\
& $2 \mathrm{hr}$ & $64.82 \pm 4.40$ & $92.33 \pm 6.80$ & $89.34 \pm 5.12$ & $70.93 \pm 4.97$ \\
Hirudin $(0.6 \mathrm{mg} / \mathrm{kg} / \mathrm{hr})$ & $6 \mathrm{hr}$ & $46.02 \pm 4.61 \dagger$ & $97.59 \pm 10.2 \dagger$ & $79.25 \pm 5.13$ & $39.35 \pm 4.96 \dagger$ \\
& $2 \mathrm{hr}$ & $71.17 \pm 4.09^{*}$ & $93.84 \pm 4.91$ & $79.71 \pm 6.15$ & $83.39 \pm 4.40 \dagger$ \\
& $6 \mathrm{hr}$ & $47.23 \pm 3.99 \dagger$ & $83.94 \pm 5.69$ & $108.3 \pm 8.70^{*}$ & $46.22 \pm 5.74 \dagger$ \\
\hline
\end{tabular}

${ }^{*} \mathrm{p}<0.05$ as compared with the endotoxin control group.

$\mathrm{tp}<0.01$.

$\ddagger p<0.001$.

stimulates platelet aggregation, with both effects leading to the formation of stable microthrombi. Exhaustion of ATIII and protein C-the main inhibitors of coagulation-could perpetuate fibrin generation, ${ }^{4,5}$ thus allowing the appearance of microvascular thrombi in various organs, and subsequent MOF. ${ }^{6}$

The fibrinolytic system, which lyses fibrin polymers, also seems to play an important role in the pathogenesis of DIC. Plasmin, the key enzyme in fibrinolysis, is generated through the activation of plasminogen by t-PA. The activity of t-PA is controlled by PAI-1. A marked increase in PAI-1 activity subsequent to endotoxin infusion has been reported in healthy human subjects as well as in animal models and cultured endothelial cells. ${ }^{7-9}$ High activities of PAI- 1 and low activities of t-PA have been found in patients with sepsis. ${ }^{10,11} \mathrm{Re}$ duced fibrinolytic activity could contribute to the persistence of fibrin deposits in such cases.

Consequently, a therapeutic approach that reduces thrombin activity and improves fibrinolysis may be of interest, as suggested by preliminary studies with experimentally induced DIC. ${ }^{12-14}$

Hirudin, a polypeptide initially isolated from the leech Hirudo medicinalis and currently available in recombinant form, is a selective thrombin inhibitor that exhibits several characteristics that make it an attractive agent for the management of DIC; for instance, it does not require cofactors such as ATIII or heparin cofactor II for its activation, and it can effectively inhibit clot-bound thrombin in vitro. ${ }^{15,16}$ Additionally, studies have pointed to a role of $\mathrm{r}$ hirudin in improving endogenous fibrinolysis, although there is no agreement about this. ${ }^{17-20}$ However, human and animal studies have shown that r-hirudin may be useful in the treatment of venous and arterial thrombosis, ${ }^{21}$ and experimental models suggest that it may be an attractive agent for treating endotoxin-induced DIC. . $^{22-26}$

The goal of the present study was to evaluate the effect of different doses of r-hirudin on mortality and kidney fibrin deposition in a rabbit model of endotoxin-induced DIC. As a secondary endpoint, we analyzed the changes in several coagulation-related and fibrinolytic parameters.

\section{METHODS}

Materials. recombinant desulfatohirudin variant 1 ( $\mathrm{Re}-$ vasc), which exhibits a specific activity of 115,000 ATU/ mg, was obtained from Ciba-Geigy, Basel, Switzerland. Endotoxin (E. coli 0111:B4) was purchased from Difco Laboratories, Detroit, Mich. Urokinase was purchased from Roger Laboratories, Barcelona, Spain.

Experimental model. Male New Zealand white rabbits (weight, 2 to $3 \mathrm{~kg}$ ) were used in the study. Animals were anesthetized with an intramuscular injection of $30 \mathrm{mg} / \mathrm{kg}$ ketamine hydrochloride and $0.002 \mathrm{mg} / \mathrm{kg}$ xylacine hydrochloride, followed by intramuscular supplements of ketamine hydrochloride given throughout the experimet. DIC was induced by infusing endotoxin, in $60 \mathrm{ml}$ of saline solution, at a rate of $100 \mu \mathrm{g} / \mathrm{kg} / \mathrm{hr}(10 \mathrm{ml} / \mathrm{hr})$ through the marginal ear vein of rabbits over a period of 6 hours.

Treatments were begun simultaneously with endotoxin infusion, through the contralateral marginal ear vein. Five groups of animals were established, containing 10 animals each. Treatment groups (low-, medium-, and high-dose r-hirudin) were given $0.05,0.3$, and $0.6 \mathrm{mg} / \mathrm{kg} / \mathrm{hr}$ r-hirudin in $60 \mathrm{ml}$ of saline solution over a period of 6 hours $(10$ $\mathrm{ml} / \mathrm{hr}$ ). The endotoxin control group was infused with saline solution as placebo (at a rate of $10 \mathrm{ml} / \mathrm{hr}$ ) over a period of 6 hours. Ten further rabbits, which were given neither endotoxin nor $\mathbf{r}$-hirudin, were infused with saline solution through both marginal ear veins over a period of 
Table I. Continued

\begin{tabular}{lll}
\hline $\begin{array}{c}\text { Plasminogen } \\
\text { (\%) }\end{array}$ & \multicolumn{1}{c}{$\begin{array}{c}\text { t-PA } \\
\text { (\%) }\end{array}$} & \multicolumn{1}{c}{$\begin{array}{c}\text { PAl-I } \\
\text { (\%) }\end{array}$} \\
\hline $93.18 \pm 3.40$ & $76.76 \pm 18.3$ & $138.38 \pm 19.2 \dagger$ \\
$94.40 \pm 3.03 \ddagger$ & $105.7 \pm 15.4^{\star}$ & $128.79 \pm 12.7 \ddagger$ \\
$88.68 \pm 3.88$ & $70.04 \pm 4.48$ & $564.01 \pm 11.1$ \\
$74.99 \pm 2.88$ & $61.81 \pm 7.44$ & $1178.3 \pm 31.2$ \\
$85.83 \pm 4.83$ & $94.64 \pm 5.64^{\star}$ & $388.60 \pm 20.4 \dagger$ \\
$81.30 \pm 3.52$ & $108.7 \pm 7.87 \dagger$ & $1147.5 \pm 78.4$ \\
$106.3 \pm 6.58$ & $82.10 \pm 6.53$ & $384.42 \pm 14.8 \dagger$ \\
$98.65 \pm 8.79 \dagger$ & $85.86 \pm 8.55^{\star}$ & $1284.3 \pm 69.9$ \\
$87.29 \pm 10.7$ & $107.8 \pm 14.9 \dagger$ & $326.77 \pm 51.5 \dagger$ \\
$87.15 \pm 9.64$ & $146.1 \pm 19.1 \ddagger$ & $933.96 \pm 165.1$ \\
\hline
\end{tabular}

6 hours $(10 \mathrm{ml} / \mathrm{hr})$, and served as an additional control group.

Surviving rabbits were killed at 24 hours after the start of each experiment, with an intravenous injection of 60 $\mathrm{mg} / \mathrm{kg}$ pentobarbital sodium (Nembutal). Kidneys were extracted from all animals (survivors and nonsurvivors) for subsequent histologic study.

Sample collection and handling. Blood samples were collected via a catheter inserted into the femoral artery before the endotoxin infusion was begun, and again after 2 and 6 hours. The blood samples were collected in $3.2 \%$ citrate at a ratio of 9 volumes of blood to 1 volume of citrate. Blood for measurement of t-PA activity was collected in Stabilyte tubes (Biopool, Umea, Swerlen) to avoid interference by inhibitors of t-PA. Blood samples for measurement of fibrinogen, ATIII, protein C, plasminogen, PAI-1, and t-PA activity were kept on ice for no more than 2 hours. Platelet-poor plasma was obtained by centrifugation at $1600 \mathrm{~g}$ for 20 minutes at $4^{\circ} \mathrm{C}$, and was stored at $-70^{\circ} \mathrm{C}$ until assayed. Tubes containing $\mathrm{K}_{3}$ EDTA were used to collect blood for platelet counts.

Laboratory methods. Platelets were counted in an automated STKS counter (Coulter, Inc., Hialeah, Fla.) Fibrinogen was measured according to the method of Clauss. ${ }^{27}$ ATIII, ${ }^{28}$ protein $\mathrm{C},{ }^{29}$ plasminogen, ${ }^{30} \mathrm{t}$-P A activity, $^{31}$ and PAI-1 activity ${ }^{32}$ were measured with commercially available assays based on chromogenic substrates (Coamatic ATIII, Coamatic Protein C, Coamatic Plasminogen, Coatest t-PA, and Coatest PAI; Chromogenix, Stockholm, Sweden).

Histologic examination. Kidney sections were fixed in formalin, embedded in paraffin, stained with Masson trichrome, and examined for the presence of fibrin microthrombi by a pathologist unaware of the experimental design used in the study. Tissue sections were scored for fibrin microthrombi on a scale of 0 to 4 , as previously described. ${ }^{12}$ In brief, a score of 0 indicated the absence of fibrin, a score of 1 indicated partial fibrin deposition in some glomeruli, a score of 2 indicated partial deposition of fibrin in all glomeruli, a score of 3 signified large quantities of fibrin in all glomeruli, and a score of 4 signified the presence of fibrin thrombi in glomerular capillaries and in noncapillary vessels.

Data analysis. Results at 2 and 6 hours were converted to percentages, with a value of $100 \%$ assumed for basal data, and were expressed as mean \pm SEM. Student's $t$ test was used to seek differences between the endotoxin control and saline solution control groups. One-way ANOVA, followed by Tukey's B test for multiple comparisons, was used to compare the endotoxin and r-hirudin groups. The Kruskal-Wallis test, followed by the MannWhitney $\mathbf{U}$ test, was used to compare fibrin deposition in the endotoxin control and treatment groups. Differences in mortality rates at 24 hours were assessed with Fisher's exact test. Differences between surviving and nonsurviving animals in hemostatic parameters were assessed with Student's $t$ test. Possible correlations between kidney fibrin deposition and hemostatic parameters were evaluated with Spearman's rank correlation test.

\section{RESULTS}

Table I shows the plasma levels, expressed in percentages with respect to the basal values, which were assumed to be $100 \%$, of the different coagulation-related and fibrinolytic parameters analyzed throughout the study in the saline solution control, endotoxin control, and treated groups of animals.

Effects of saline solution. No changes were found in hemostatic parameters during saline solution infusion (Table I). No rabbits died or showed evidence of kidney fibrin deposition with saline solution infusion.

Effects of endotoxin infusion in rabbits given no treatment. Measurements made at 6 hours of infusion showed a significant decrease, with respect to the saline solution group, in platelet count, fibrinogen and protein $\mathrm{C}$ concentrations $(p<0.001)$, and ATIII $(p<0.05)$. Platelet numbers and the protein $\mathrm{C}$ concentration decreased significantly at 2 hours $(p<0.01)$ after the beginning of infusion. Levels of plasminogen and t-PA activity were significantly lower at 6 hours after the beginning of endotoxin infusion ( $p<0.001$ and $p<0.05$, respectively) than at the corresponding time in the saline solution group. PAI- 1 activity increased dramatically at 2 and 6 hours after the beginning of endotoxin infusion $(p<0.001)$.

Intense fibrin deposition was detected in most of the endotoxin-treated rabbits, even in noncapillary vessels. The average value for fibrin deposition according to the score described earlier was $2.61 \pm$ 0.34 , which was significantly higher $(p<0.01$ than that in rabbits given only saline solution (score $=0$ ).

Seven of the 10 rabbits in the endotoxin group died within the first 24 hours after endotoxin infu- 

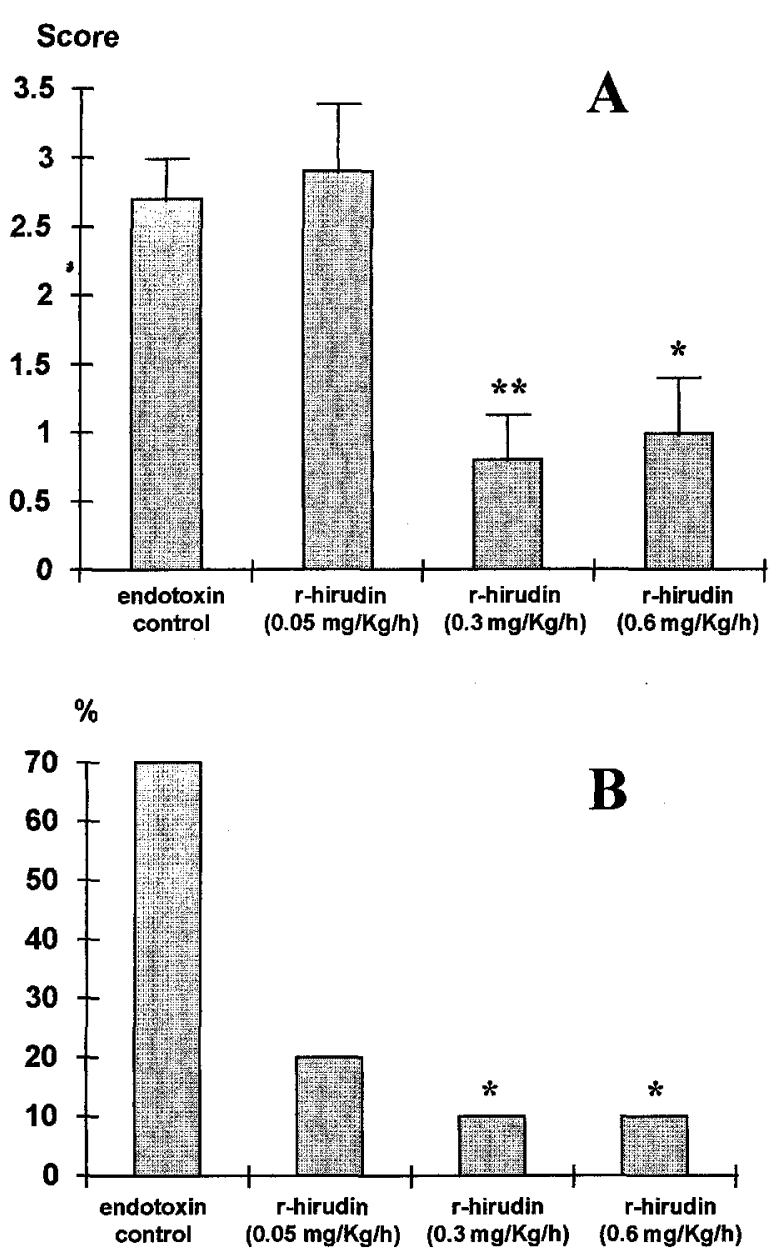

Fig. 1. Score for fibrin deposition in kidneys (A) and mortality rate (B) in endotoxin control group and in rabbits receiving r-hirudin (low, medium, and high doses). Score values are expressed as mean \pm SEM and mortality as percentage. ${ }^{*} p<0.05$ and ${ }^{* *} p<0.01$ as compared with the endotoxin control group.

sion, whereas no animals died in the saline solution control group.

Effects of r-hirudin on DIC. We found that infusion of medium and high doses of $r$-hirudin efficiently ameliorated the platelet decrease at 6 hours after the beginning of endotoxin infusion by comparison with the endotoxin control group $(p<0.01)$, and also at 2 hours by comparison with the high-dose endotoxin group $(p<0.05)$. A reduction in fibrinogen consumption was observed in the medium-dose group $(p<$ 0.01 ). As shown in Table I, high-dose r-hirudin prevented a decrease in ATIII concentration $(p<0.05$ at 6 hours), whereas both medium ( $p<0.01$ at 6 hours) and high ( $p<0.01$ at 2 and 6 hours) doses of r-hirudin diminished the decrease in protein $\mathrm{C}$ concentration. Low doses of r-hirudin did not reduce the endotoxininduced activation of coagulation.
With regard to fibrinolytic parameters, all doses of r-hirudin reduce the increase in PAI-1 activity in blood samples taken at 2 hours after the beginning of endotoxin infusion $(p<0.01)$, although the activity values were still higher than the respective baseline values, and no effect was seen at 6 hours. An interesting finding was the significant prevention of the decrease in t-PA activity that was achieved with all three doses of r-hirudin at 6 hours after the beginning of endotoxin infusion, and at 2 hours with the low and high doses (Table I). In addition, the medium dose of r-hirudin corrected the mild decrease in plasminogen observed at 6 hours in the endotoxin control group.

The high and medium doses of r-hirudin significantly reduced fibrin deposition in the kidneys of test animals (scores: $1.05 \pm 0.45, p<0.05$; and $0.83 \pm 0.35, p<0.01$, respectively), whereas no significant effect was observed with the lowest dose (score: $3.05 \pm 0.44$ ) (Fig. 1).

Two of 10 rabbits (20\%) died after treatment with low-dose hirudin, whereas only 1 of $10(10 \%)$ died after treatment with the medium and high doses. The mortality rate in the latter two groups was significantly lower than in the endotoxin control group $(p<0.05)$ (Fig. 1).

Hemostatic parameters in relation to mortality. When comparing the changes observed in the hemostatic parameters analyzed in surviving rabbits $(n=29)$ with those in animals that died in the endotoxin and treatment groups $(\mathrm{n}=11)$, we found that plasma protein $\mathrm{C}$ activity was significantly lower at 2 and 6 hours $(p<0.001)$ in animals that died within the 24 hours after infusion $(54.36 \% \pm 4.42 \%$ and $12.98 \%$ $\pm 3.58 \%)$ than in survivors $(76.54 \% \pm 2.67 \%$ and $36.43 \% \pm 3.48 \%$ ). A decrease in the platelet count at 2 hours $(51.98 \% \pm 6.34 \%$ vs $65.52 \% \pm 2.4 \%)$ and at 6 hours $(26.06 \% \pm 5.94 \%$ vs $40.35 \% \pm 2.94 \%)$ was more evident in nonsurviving rabbits than in survivors $(p<0.05)$. Likewise, fibrinogen consumption at 6 hours $(58.92 \% \pm 4.6 \%$ vs $85.63 \% \pm 4.62 \%)$ was significantly higher in nonsurviving rabbits $(p<$ $0.05)$. However, no differences in other parameters were assessed. On the other hand, nonsurviving rabbits showed more intense kidney fibrin deposition than did surviving animals $(2.75 \pm 0.36$ vs $1.59 \pm$ $0.26)$. Although this last difference was not significant, it was at the limit of statistical significance $(p=$ 0.06).

Remarkably, a strong positive correlation was found between protein $\mathrm{C}$ consumption and fibrin deposition at 2 and 6 hours $(r=0.42, p<0.05$, and $r=0.68, p<0.001$, respectively). There was also a positive correlation between kidney fibrin deposi- 
tion and the decrease in platelet numbers and fibrinogen at 6 hours $(r=0.35$ and $r=0.37, p<0.05)$.

\section{DISCUSSION}

We studied the effects of several doses of r-hirudin on an endotoxin-induced DIC model in rabbits. We found a significant decrease in platelet count; in fibrinogen, ATIII, protein C, and plasminogen concentration and in t-PA activity; a dramatic increase in PAI-1 activity; intense kidney fibrin deposition; and a high mortality rate after endotoxin infusion.

r-Hirudin decreased the consumption of platelets, fibrinogen, ATIII, and protein C, and also decreased fibrin deposition and the mortality rate in treated animals. These results are in accord with those in previous studies showing that $\mathbf{r}$-hirudin can decrease the consumption of platelets, fibrinogen, and ATIII, as well as diminishing increases in fibrin monomers, thrombin-antithrombin complexes, fibrinogen-fibrin degradation products, and fibrin deposition in different animal models of endotoxininduced DIC. ${ }^{22-24}$ Furthermore, a prior study with rabbits infused with gram-negative bacteria showed that mortality in animals treated with r-hirudin and antibiotic was lower than in animals treated with heparin and antibiotic. ${ }^{25}$

The improvement in protein $\mathrm{C}$ concentration with r-hirudin treatment was remarkable among the changes observed in coagulation parameters. The chief cause of protein $\mathrm{C}$ deficiency in endotoxininduced DIC is not a decrease in production of this protein, but the huge generation of thrombin that occurs in the condition, as previously demoristrated in baboons. ${ }^{33}$ The inhibition of thrombin by r-hirudin decreases the formation of thrombin-thrombomodulin complexes, thus avoiding activation of protein $\mathrm{C}$ and its subsequent exhaustion. Moreover, a beneficial effect of treatment with r-hirudin in preventing protein $C$ consumption can be assumed in endotoxin-induced DIC, since protein C levels in animals that died within 24 hours after endotoxin infusion in the present study were significantly lower than those in animals that did not die. These results are in accord with the recent finding that the severity of protein $\mathrm{C}$ deficiency in human sepsis is greater in nonsurvivors than in survivors, and correlates with the extent of the skin lesion, which in turn reflects the severity of microvascular thrombosis in the condition. ${ }^{34}$ Furthermore, in a model of gramnegative sepsis in baboons, a monoclonal antibody able to block the activation of protein $\mathrm{C}$ increases mortality, which is reduced by protein $\mathrm{C}$ infusion. ${ }^{35}$ In the present study, we describe a strong correlation between the decrease in protein $\mathrm{C}$ concentra- tion and the intensity of kidney fibrin deposition. Considering these findings collectively, it is tempting to speculate that protein $\mathrm{C}$ plays an etiologic role in the development of microthrombosis, although the possibility that this molecule is merely a sensitive and reliable marker of DIC cannot be excluded.

Although endotoxin-induced inhibition of fibrinolysis does not seem to be the critical factor in kidney fibrin deposition, it is obvious that an improvement in fibrinolysis could partly prevent fibrin deposition. ${ }^{12-14,36,37}$ In our endotoxin-induced DIC model, r-hirudin modified fibrinolysis. We found that it reduced PAI-1 activity at 2 hours and prevented the decrease in t-PA activity, enhancing its fibrinolytic potential. To our knowledge, no prior studies have been done of the effect of r-hirudin on fibrinolytic changes occurring during endotoxin-induced DIC. Although the infusion of r-hirudin into chimpanzees given endotoxin does not prevent impairment of fibrinolysis, it should be noted that the amount of endotoxin infused $\left(4 \mathrm{ng} / \mathrm{kg}\right.$ ) failed to induce DIC. ${ }^{17}$ On the other hand, an improvement in fibrinolysis has been suggested after treatment with r-hirudin in a rabbit model of chronic venous thrombosis, ${ }^{18}$ and a recent study has shown that r-hirudin can enhance the extent of endogenous fibrinolysis in a model of jugular venous thrombosis, although PAI-1 and t-PA activity remained unchanged. ${ }^{19}$ In vitro experiments have shown that endothelial cell incubation with thrombin induces a significant increase in both PAI- antigen and activity levels, as well as in PAI-1 mRNA. ${ }^{38-40}$ Therefore, inhibition of thrombin could contribute to reduced production and secretion of PAI-1 by endothelial cells. On the other hand, prevention by $r$-hirudin of the decrease in t-PA activity induced by endotoxin could be due to the ability of r-hirudin to promote t-PA release from endothelial cells, as previously shown by our group. ${ }^{20}$ Taken collectively, this information suggests that $r$-hirudin partly prevents hypofibrinolysis by reducing the increase in PAI-1 occurring in endotoxemia as well as by enhancing endothelial t-PA release.

The lowest dose of r-hirudin used in the present study did not correct the impairment in coagulation induced by endotoxin, but did improve fibrinolysis by acting on both t-PA and PAI-1 activity, although these modifications were inadequate to produce a reduction in fibrin deposition. Also, although a clear tendency toward reduced mortality was observed with r-hirudin, the mortality rate was not significantly reduced, probably as a consequence of the number of animals used in the experiment. One explanation for the lack of utility of r-hirudin in improving coagulation and reducing kidney fibrin 
deposition in this case may be that the dose used was from 2.5- to 5-fold lower than doses found to be effective in other experimental models of sepsis. ${ }^{24,25}$ Although this dose (and even smaller doses) has been useful in human DIC, it is important to note that these cases of DIC were not the fulminant DIC induced by gram-negative bacteria. ${ }^{41,42} \mathrm{On}$ the other hand, it should be noted that the dose of hirudin effective in inhibiting thrombin depends on the species in which it is used, since the inhibitory rate constant of hirudin for thrombin varies among species. Another noteworthy observation about the low r-hirudin dose used in the present study was that despite its tendency to reduce the mortality rate among treated animals, it did not diminish kidney fibrin deposition. One possible explanation could be that such a dose might have succeeded in preventing microthrombi in other organs, thus avoiding MOF, with a subsequent reduction in mortality. Kidneys are thought to be especially prone to fibrin formation, with the result that higher doses of r-hirudin would be needed to arrest the development of microthrombi, a concept coherent with the results obtained with the medium and high doses of r-hirudin in the present study.

In a further step, we analyzed the possible correlations between hemostatic parameters and kidney fibrin deposition, mortality, or both, to investigate the pathophysiologic mechanisms operating in DIC and to identify prognostic markers in this condition. As expected, the decrease in platelet count and fibrinogen concentration was significantly greater in rabbits that died within 24 hours after the beginning of the experiment than in those that survived, suggesting that these two parameters might have a certain prognostic value in DIC. That both parameters also correlated with kidney fibrin deposition is not surprising, since both parameters play a critical role in the formation of microvascular thrombi. Some investigators have claimed that ATIII levels could have prognostic value in human DIC, and could also be useful in monitoring treatment, ${ }^{43-45}$ but we did not find differences in ATIII behavior in surviving and nonsurviving animals. However, nonsurviving rabbits showed a significantly greater decrease in protein $\mathrm{C}$ concentration, which correlated with kidney fibrin deposition. These findings suggest that protein $\mathrm{C}$ may not only be a reliable prognostic marker in DIC, but may also play a role in the pathogenesis of microthrombosis, as has recently been suggested. ${ }^{34}$

We conclude that treatment with r-hirudin can decrease, in a dose-dependent manner, both kidney fibrin deposition and the mortality rate in a model of endotoxin-induced DIC in rabbits. In the light of our data, this direct inhibitor of thrombin may have a twofold benefit in improving the function of anticoagulant systems, particularly by preventing exhaustion of protein $\mathrm{C}$, and enhancing fibrinolytic potential. If these findings apply to humans, our results would suggest that administration of r-hirudin may improve the survival of patients with endotoxininduced DIC. However, because r-hirudin in our study was given at the same time as exposure to endotoxin, we cannot confirm that it is efficacious once DIC has begun, and further studies are needed to assess this issue.

We thank Dr. G. F. Pay of Ciba-Geigy, Horsham, England, for providing the recombinant hirudin (Revasc) used in our study. We also thank Mercedes Fernandez and Yolanda Azcona for technical assistance.

\section{REFERENCES}

1. Bick RL. Disseminated intravascular coagulation. Hematol Oncol Clin North Am 1992;6:1259-85.

2. Kreger BE, Craven DE, McCabe WR. Gram-negative bacteremia. IV. Re-evaluation of clinical features and treatment in 612 patients. Am J Med 1980;68:344-55.

3. Warr TA, Mohan Rao LV, Rapaport SI. Disseminated intravascular coagulation in rabbits induced by administration of endotoxin or tissue factor: effect of anti-tissue factor antibodies and measurement of plasma extrinsic pathway inhibitor activity. Blood 1990;75:1481-9.

4. Fenton JW II. Thrombin. Ann NY Acad Sci 1986;485:5-15.

5. Malar RA, Kleiss AJ, Griffin JH. Mechanism of action of human activated protein $\mathrm{C}$, a thrombin-dependent anticoagulant enzyme. Blood 1982;59:1067-72.

6. Robboy SJ, Major MC, Colman RW, Minna JD. Pathology of disseminated intravascular coagulation (DIC). Analysis of 26 cases. Hum Pathol 1972;3:327-43.

7. Colucci M, Paramo JA, Collen D. Generation in plasma of a fast-acting inhibitor of plasminogen activator in response to endotoxin stimulation. J Clin Invest 1985;75:818-24.

8. Crutchley DJ, Conanan LB. Endotoxin induction of an inhibitor of plasminogen activator in bovine pulmonary artery endothelial cells. J Biol Chem 1986;261:154-9.

9. Suffredini AF, Harpel PC, Parrillo JE. Promotion and subsequent inhibition of plasminogen activation after administration of intravenous endotoxin to normal subjects,. N Engl J Med 1989;320:1165-72.

10. Paramo JA. Fernandez FJ, Rocha E. Plasminogen activator inhibitor activity in bacterial infection. Thromb Haemost 1988;59:451-4.

11. Paramo JA, Perez JL, Serrano M, Rocha E. Types 1 and 2 plasminogen activator inhibitor and tumor necrosis factor alpha in patients with sepsis. Thromb Haemost 1990;64:3-6.

12. Gomez C, Paramo JA, Colucci M, Rocha E. Effect of heparin and/or antithrombin III on the generation of endotoxininduced plasminogen activator inhibitor. Thromb Haemost 1989;62:694-8.

13. Paloma MJ, Paramo JA, Rocha E. Effects of DDAVP on endotoxin-induced intravascular coagulation in rabbits. Thromb Haemost 1992;68:306-9.

14. Paloma MJ, Paramo JA, Rocha E. Endotoxin-induced intra- 
vascular coagulation in rabbits: effect of tissue plasminogen activator vs urokinase on PAI generation, fibrin deposits, and mortality. Thromb Haemost 1995;74:1578-82.

15. Markward F. Hirudin and derivatives as anticoagulant agents. Thromb Haemost 1991;66:141-52.

16. Weitz JI, Hudoba M, Massel D, et al. Clot-bound thrombin is protected from inhibition by heparin-antithrombin III but is susceptible to inactivation by antithrombin III-independent inhibitors. J Clin Invest 1990;86:385-91.

17. Biemond BJ, Levi $\mathrm{M}$, Ten Cate $\mathrm{H}$, et al. Plasminogen activator and plasminogen activator inhibitor 1 release during experimental endotoxaemia in chimpanzees: effect of interventions in the cytokine and coagulation cascades. Clin Sci Colch 1995;88:587-94.

18. Klement P, Smith S. Hirsh J, Weitz J. Hirudin, but not heparin, accelerates physiologic fibrinolysis in a rabbit chronic venous thrombosis model [abstract]. Thromb Haemost 1995;73:2118.

19. Biemond BJ, Friederich PW, Levi M, et al. Comparison of sustained antithrombotic effects of inhibitors of thrombin and factor Xa in experimental thrombosis. Circulation 1996; 93:153-60.

20. Chorda C, Paramo JA, Rocha E. Comparison of the effects of unfractionated heparin, low molecular weight heparin and hirudin (Revasc ${ }^{\mathrm{TM}}$ ) on the fibrinolytic potential of cultured human umbilical vein endothelial cells. Fibrinolysis 1996;10: 43-8.

21. Weitz JI, Califf RM, Ginsberg JS, et al. New antithrombotics. Chest 1995;108(suppl 4):471S-85S.

22. Ishikawa A, Hafter R, Seemuller U, et al. The effect of hirudin on endotoxin-induced disseminated intravascular coagulation (DIC). Thromb Res 1980;19:351-8.

23. Hoffmann $\mathrm{H}$, Siebeck M, Spannagl M, et al. Effect of recombinant hirudin, a specific inhibitor of thrombin, on endotoxin-induced intravascular coagulation and acute lung injury in pigs. Am Rev Respir Dis 1990;142:782-8.

24. Dickneite G, Czech J, Keuper H. Formation of fibrin monomers in experimental disseminated intravascular coagulation and its inhibition by recombinant hirudin. Circ Shock 1994; 42:183-9.

25. Dickneite G, Czech J. Combination of antibiotic 1reatment with the thrombin inhibitor recombinant hirudin for the therapy of experimental Klebsiella pneumoniae sepsis. Thromb Haemost 1994;71:768-72.

26. Zawilska $\mathrm{K}$, Zozulinska $\mathrm{M}$, Turowiecka $\mathrm{Z}$, et al. The effects of a long-acting recombinant hirudin (PEG-hirudin) on experimental disseminated intravascular cephalothin (DIC) in rabbits. Thromb Res 1993;69:315-20.

27. Clauss A. Gerinnungs physiologische schnell methode zur bestimmung des fibrinogens. Acta Haematol 1957; 17:237.28.

28. Andersson EN, Menschik M, van Voorhuizen H. New chromogenic ATIII activity kit which is sensitive to heparin cofactor II and designed for use on automated instruments [abstract]. Thromb Haemost 1991;65:766.

29. Vinazzer $H$, Pangraz U. Protein C: comparison of different assays in normal and abnormal plasma samples. Thromb Res 1987;46:1-8.

30. Krishnamurti C, Barr CF, Hasset MA, et al. Plasminogen activator inhibitor: a regulator of ancrod-induced fibrin deposition in rabbits. Blood 1987;69:798-803.

31. Verheijen $\mathrm{JH}$, Mullaat E, Chang GTG, et al. A simple, sensitive spectrophotometric assay for extrinsic (tissue-type) plasminogen activator applicable to measurements in plasma. Thromb Haemost 1982;48:266-9.

32. Paramo JA, Alfaro MJ, Rocha E. Postoperative changes in the plasmatic levels of tissue-type plasminogen activator and its fast-acting inhibitor. Relationship to deep vein thrombosis and influence of prophylaxis. Thromb Haemost 1985;54: 713-6.

33. Taylor FB Jr, Chang A, Esmon CT, et al. Protein C prevents the coagulopathic and lethal effects of Escherichia coli infusion in the baboon. J Clin Invest 1987;79:918-25.

34. Fijnvandraat K, Derkx B, Peters M, et al. Coagulation activation and tissue necrosis in meningococcal septic shock: Severely reduced protein $\mathrm{C}$ levels predict a high mortality. Thromb Haemost 1995;73:15-20.

35. Esmon CT, Taylor FB Jr, Snow TR. Inflammation and coagulation: linked processes potentially regulated through a common pathway mediated by protein $\mathrm{C}$. Thromb Haemost 1991;66:160-5.

36. Krishnamurti C, Bolan C, Colletin CA, et al. Role of plasminogen activator inhibitor-1 in promoting fibrin deposition in rabbits infused with ancrod or thrombin. Blood 1993;82: $3631-6$.

37. Krishnamurti C, Keyt B, Maglasang P, Alving BM. PAI-1resistant t-PA: low doses prevent fibrin deposition in rabbits with increased PAI-1 activity. Blood 1996;87:16-9.

38. Van Hinsberg VWM, Sprengers DE, Kooistra T. Effect of thrombin on the production of plasminogen activators and PA inhibitor 1 by human foreskin microvascular endothelial cells. Thromb Haemost 1987;57:148-53.

39. Gelehrter TD, Szyncer-Laszuk R. Thrombin induction of plasminogen activator inhibitor in cultured human endothelial cells. J Clin Invest 1986;77:165-9.

40. Hanss M, Collen D. Secretion of tissue-type plasminogen activator and plasminogen activator inhibitor by cultured human endothelial cells: modulation by thrombin, endotoxin, and histamine. J Lab Clin Med 1987;109:97-104.

41. Breddin HK, Markwardt F. Clinical experience with hirudin in disseminated intravascular coagulation [abstract]. Thromb Haemost 1993;69:1299.

42. Saito M, Asakura H, Jokaji $H$, et al. Recombinant hirudin for the treatment of disseminated intravascular coagulation in patients with hematological malignancy. Blood Coagul Fibrinolysis $1995 ; 6: 60-4$.

43. Laemmle B, Tran TH, Ritz R, Duckert F. Plasma pre-kallikrein, factor XII, antithrombin III, C1-inhibitor, and $\alpha 2$ macroglobulin in critically ill patients with suspected disseminated intravascular coagulation (DIC). Am J Clin Pathol 1984;82:396-404.

44. Lauritsen B. Faber V, Brock A, et al. Disseminated intravascular coagulation, antithrombin III, and complement in meningococcal infections. Acta Med Scand 1981;209:221-7.

45. Bick RL, Bick MP, Fekete LF. Antithrombin III patterns in disseminated intravascular coagulation. Am J Clin Pathol 1980;73:577-83. 